\title{
USO DE PALHA DE AÇO COMERCIAL PARA O TRATAMENTO DE EFLUENTES CONTENDO CROMO HEXAVALENTE PROVENIENTES DE PROCESSOS DE ELETROCOLORAÇ̃̃o DE AÇOS INOXIDÁVEIS
}

\author{
Kallyni Irikura ${ }^{a}$, Marcelo Braga Bueno Guerrab, Nerilso Bocchi ${ }^{a, *}$, Romeu Cardozo Rocha-Filho ${ }^{\text {a }}$, Elaine Kikuti ${ }^{\mathrm{c}}$ e \\ Sonia Regina Biaggio ${ }^{\mathrm{a}}$ \\ aDepartamento de Química, Universidade Federal de São Carlos, CP 676, 13560-970 São Carlos - SP, Brasil \\ ${ }^{\mathrm{b} S c h o o l ~ o f ~ N a t u r a l ~ S c i e n c e s, ~ B l a c k ~ H i l l s ~ S t a t e ~ U n i v e r s i t y, ~} 1200$ University St., 57799, Spearfish - SD, EUA \\ ${ }^{c}$ Faculdade de Ciências Integradas do Pontal, Universidade Federal de Uberlândia, 38304-402 Ituiutaba - MG, Brasil
}

Recebido em 24/05/2017; aceito em 20/09/2017; publicado na web em 08/11/2017

\begin{abstract}
USE OF COMMERCIAL STEEL WOOL PADS FOR THE TREATMENT OF WASTEWATER CONTAINING HEXAVALENT CHROMIUM FROM ELECTROCOLORATION PROCESSES OF STAINLESS STEELS. Residual solutions containing Cr(VI) ions can be harmful to the environment as well as to human health. Hence, practical and efficient methods for the treatment of such solutions are welcome. In this note, the treatment with commercial steel wool pads of a $\mathrm{Cr}(\mathrm{VI})$ residual solution from electrochemical coloration processes of stainless steel is described in detail. Successful treatment was achieved when an amount of steel wool equivalent to $20 \%$ in excess in relation to the theoretical stoichiometric amount was used, followed by chemical precipitation with sodium hydroxide up to $\mathrm{pH} 10-11$ and separation by filtration under reduced pressure. The treatment yielded a final solution with concentrations of $\mathrm{Cr}(\mathrm{III})$ and $\mathrm{Cr}(\mathrm{VI})$ ions of only $0.29 \pm 0.02 \mathrm{mg} \mathrm{L}^{-1}$ and $<0.01 \mathrm{mg} \mathrm{L}^{-1}$, respectively. These concentration values are significantly lower than the maximum limits established by CONAMA for industrial wastewaters, attesting the efficiency of the treatment.
\end{abstract}

Keywords: removal of $\mathrm{Cr}(\mathrm{VI})$ ions; reduction; precipitation; wastewater treatment.

\section{INTRODUÇÃO}

O cromo é um metal de transição que cumpre um papel importante na sociedade moderna. $\mathrm{O}$ fato de possuir propriedades interessantes, dentre as quais a passividade, confere a este elemento um amplo uso na proteção à corrosão, sendo, portanto, muito empregado em metalurgia, principalmente na produção de ligas ferrosas como os aços inoxidáveis. Além disso, espécies solúveis de cromo, principalmente na forma hexavalente, foram utilizadas em laboratórios, no passado, como solução sulfocrômica para limpeza de vidrarias ${ }^{1}$ e, atualmente, são muito utilizadas em indústrias de couro e galvanoplastia, ${ }^{2-4}$ incluindo aquelas que operam processos de eletropolimento ${ }^{5}$ e coloração $0^{6-12}$ de aços inoxidáveis. Neste último caso, na grande maioria dos processos são empregadas soluções constituídas por ácidos fortemente oxidantes como a mistura concentrada de ácido sulfúrico e anidrido crômico/trióxido de cromo. ${ }^{6-10,12}$ Esta solução, quando submetida a sucessivos processos de coloração, perde a capacidade de reproduzir as cores superficiais desejadas (aquelas obtidas inicialmente), inviabilizando seu uso nos posteriores processos de coloração do aço. Embora haja um decréscimo da concentração ácida ao longo do uso desta solução, ao final seu valor ainda é elevado. Além disso, a solução apresenta concentrações apreciáveis de íons metálicos provenientes do substrato de aço inoxidável, tais como íons ferro, níquel, cromo etc. Os íons cromo estão presentes nessa solução predominantemente na forma hexavalente, que é um forte agente oxidante, com alta toxicidade, solubilidade e mobilidade em ambientes aquáticos e terrestres. Por isto, a solução ácida residual de processos de coloração de aços (ácido sulfúrico e anidrido crômico/ trióxido de cromo) deve sempre ser tratada de forma adequada antes de ser descartada; caso contrário, pode causar sérios danos ao meio ambiente (contaminação de corpos de água, solo, plantas e animais) e aos seres humanos (aumento da incidência de câncer). ${ }^{13,14}$ Apesar dos

*e-mail: bocchi@ufscar.br sérios problemas causados pelos íons cromo na forma hexavalente, é importante ressaltar que sua forma trivalente é de fundamental importância para o organismo humano; sua ausência na alimentação pode causar sérias complicações de saúde, como diabetes e problemas cardiovasculares. ${ }^{15}$ Esses dois estados de oxidação do cromo são os mais estáveis e, consequentemente, os mais comumente encontrados no meio ambiente.

Diante da importância tecnológica do uso de soluções aquosas ácidas contendo íons cromo na forma hexavalente para alguns setores industriais e dos seus efeitos toxicológicos, o CONAMA - Conselho Nacional do Meio Ambiente - estabeleceu, por meio da Resolução no 430 de 13 de maio de 2011, concentrações limites máximas de cromo hexavalente e cromo trivalente em efluentes industriais a serem descartados no meio ambiente de $0,1 \mathrm{mg} \mathrm{L}^{-1}$ e $1,0 \mathrm{mg} \mathrm{L}^{-1}$, respectivamente. ${ }^{16}$ Portanto, para atender à legislação vigente, previamente ao seu descarte, soluções residuais contendo íons cromo nas formas hexavalente e trivalente necessitam ser adequadamente tratadas.

O tratamento mais amplamente utilizado e descrito na literatura especializada é o de redução química seguida de precipitação na forma de hidróxido. ${ }^{3,4,17-26}$ Este método consiste em reduzir os íons $\mathrm{Cr}(\mathrm{VI})$ a $\mathrm{Cr}$ (III), diminuindo-se, assim, o poder oxidante da solução residual. Na sequência, os íons Cr(III) são precipitados na forma de hidróxido de cromo, que é então separado e armazenado. Esse procedimento é realizado em meio ácido, empregando-se um dos seguintes agentes redutores: palha de aço, ${ }^{3,4,22,24}$ peróxido de hidrogênio, ${ }^{17}$ ferro metálico, ${ }^{18,23,26}$ magnetita acrescida de ferro metálico,${ }^{26}$ metabissulfito de sódio, ${ }^{18,22}$ sulfato ferroso, ${ }^{18}$ sulfato ferroso combinado com hidrossulfito de sódio ${ }^{19,20}$ ou tiossulfato de sódio. ${ }^{21}$ Após a redução dos íons $\mathrm{Cr}(\mathrm{VI})$, o pH da solução aquosa é ajustado no intervalo entre 10 e 11, com consequente precipitação do hidróxido de cromo $\left[\mathrm{Cr}(\mathrm{OH})_{3}\right]^{2,3}$ Além do tratamento de redução química, diversas outras metodologias têm sido propostas na literatura para o tratamento de soluções contendo íons $\mathrm{Cr}(\mathrm{VI})$, dentre as quais destacam-se os seguintes métodos: fotocatalítico, em que usualmente emprega-se 
dióxido de titânio $\left(\mathrm{TiO}_{2}\right)$ como fotocatalisador ${ }^{27-29}$ e é indicado para o tratamento de soluções contendo baixas concentrações de íons $\mathrm{Cr}(\mathrm{VI})$; eletroquímico, em que se usam diferentes materiais de eletrodo, tais como polímeros condutores, ${ }^{30,31}$ fibra de carbono, ${ }^{32,33}$ carbono vítreo, ${ }^{34}$ ouro e diamante dopado com boro; ${ }^{35}$ bioeletroquímico, em que se usam microrganismos para converter a energia química armazenada nos materiais biodegradáveis em corrente elétrica, com produção de outras substâncias químicas; ${ }^{36}$ biossorção, que consiste no processo de adsorção de metais tóxicos por microrganismos ativos (biossorção ativa) ou inativos (biossorção passiva). ${ }^{37-39}$ Embora eficientes, em geral esses métodos exigem aparatos mais sofisticados para o tratamento das soluções residuais contendo íons $\mathrm{Cr}(\mathrm{VI})$ e são, portanto, de maior custo de implementação.

Uma das linhas de pesquisa do LaPE - Laboratório de Pesquisas em Eletroquímica do Departamento de Química da UFSCar - é a investigação de metodologias de eletrocoloração de aços inoxidáveis via o crescimento de filmes interferentes (coloridos). Numa delas, emprega-se uma solução fortemente oxidante composta por uma mistura de ácido sulfúrico e anidrido crômico/trióxido de cromo. Ao final de sucessivos processos de coloração, a solução residual ainda contém altas concentrações de ácido e $\mathrm{Cr}(\mathrm{VI})$ na forma de íons dicromato, $\mathrm{Cr}_{2} \mathrm{O}_{7}{ }_{7}^{2-}$. Visando minimizar a toxicidade desta solução, o presente trabalho teve como objetivo avaliar uma metodologia simples e eficiente, utilizando como agente redutor palha de aço comercial, a fim de se obter uma solução tratada cuja concentração de íons $\mathrm{Cr}$ (VI) e $\mathrm{Cr}$ (III) sejam inferiores às concentrações limites máximas estabelecidas pelo CONAMA para estes íons. Este método de tratamento vem sendo empregado no LaPE desde 2004 e neste trabalho a otimização do procedimento utilizado é discutida.

\section{PARTE EXPERIMENTAL}

\section{Determinação da concentração de íons $\operatorname{Cr}(\mathrm{VI})$ na solução residual}

A solução residual investigada no presente trabalho tem como origem soluções eletrolíticas utilizadas em processos de coloração de amostras de aço inoxidável ${ }^{6-11}$ (mistura de ácido sulfúrico 5,0 mol L ${ }^{-1}$ e anidrido crômico/trióxido de cromo 2,5 $\mathrm{mol} \mathrm{L}^{-1}$ ). Quando uma determinada cor da superfície do aço não é mais reproduzida numa dada condição experimental, essa solução é renovada e aquela utilizada até então é devidamente armazenada. Portanto, a solução residual a ser tratada continha predominantemente íons dicromato, $\mathrm{Cr}_{2} \mathrm{O}_{7}{ }^{2-}$ e os íons dos elementos da liga que compõem o aço inoxidável austenítico, tais como ferro, níquel, cromo, manganês etc. ${ }^{6} \mathrm{~A}$ concentração de íons $\mathrm{Cr}_{2} \mathrm{O}_{7}^{2-}$ na solução residual foi determinada por titulação potenciométrica, utilizando uma solução de sulfato ferroso amoniacal (Synth PA) $0,1 \mathrm{~mol} \mathrm{~L}^{-1}$ previamente padronizada como titulante. Para tal, num béquer de $50 \mathrm{~mL}$ foi adicionada uma alíquota de $10 \mathrm{~mL}$ da solução residual já diluída 100 vezes e acrescida de 8,6 mL de ácido sulfúrico (Mallinckrodt 95-98\%) e 1,4 mL de ácido fosfórico (Mallinckrodt 85\%). A mistura resultante foi, então, titulada com a solução de sulfato ferroso amoniacal, utilizando uma tira de platina ( $35 \mathrm{~mm} \times 7 \mathrm{~mm} \times 0,1 \mathrm{~mm}$ ) como eletrodo indicador. O potencial deste eletrodo foi monitorado em relação a um eletrodo de referência de calomelano saturado (ECS) com auxílio de um multímetro Minipa ET-2082E. A solução titulada foi mantida sempre sob agitação magnética e em banho de água à temperatura ambiente.

\section{Tratamento da solução residual}

Antes do tratamento propriamente dito, a solução residual foi submetida a uma titulação potenciométrica similar àquela descrita no item anterior, utilizando como titulante palha (lã) de aço (ferro) $\mathrm{n}^{\circ} 0$ em substituição à solução de sulfato ferroso amoniacal. Para isto, num béquer de $2 \mathrm{~L}$ foi adicionado $1 \mathrm{~L}$ da solução residual já diluída 100 vezes e acrescida de $8,6 \mathrm{~mL}$ de ácido sulfúrico (Mallinckrodt 95-98\%) e 1,4 mL de ácido fosfórico (Mallinckrodt $85 \%$ ). Em seguida, pequenas quantidades previamente pesadas de palha de aço foram adicionadas à solução residual diluída, ao mesmo tempo em que se monitorava o potencial do eletrodo indicador de platina. Bem antes do ponto de equivalência, foram adicionadas massas de palha de aço correspondentes a $\sim 10 \%$ da massa de ferro necessária para reagir completamente com os íons dicromato da solução (quantidade estequiométrica), de acordo com a seguinte equação química: ${ }^{40}$

$\mathrm{Cr}_{2} \mathrm{O}_{7}^{2-}(\mathrm{aq})+2 \mathrm{Fe}(\mathrm{s})+14 \mathrm{H}^{+}(\mathrm{aq}) \rightarrow 2 \mathrm{Cr}^{3+}(\mathrm{aq})+2 \mathrm{Fe}^{3+}(\mathrm{aq})+7 \mathrm{H}_{2} \mathrm{O}(\mathrm{l})(1)$

Próximo do ponto de equivalência (antes e depois) foram adicionadas massas de palha de aço correspondentes a 2\% da quantidade estequiométrica. Durante este procedimento de titulação, a solução resultante foi sempre mantida sob agitação magnética e em banho de água à temperatura ambiente. Mudanças no valor do potencial do eletrodo indicador e na cor da solução titulada indicaram o momento de interromper a adição de palha de aço.

Para o tratamento, foram usados volumes de $50 \mathrm{~mL}$ da solução residual (sem qualquer diluição) acrescidos de $25 \mathrm{~mL}$ de ácido fosfórico (Mallinckrodt 85\%). O tratamento consistiu na adição de pequenas quantidades de palha de aço previamente pesadas (massas correspondentes a $\sim 10 \%$ da quantidade estequiométrica) até que a massa total de palha de aço adicionada fosse maior que aquela corresponde à quantidade estequiométrica, isto é, $105 \%, 110 \%, 115 \% \mathrm{e}$ $120 \%$ da massa de ferro necessária para reagir completamente com os íons dicromato da solução, de acordo com a equação (1).

Os íons $\mathrm{Cr}$ (III) e $\mathrm{Fe}$ (III) gerados nas soluções tratadas acima foram precipitados pela adição de hidróxido de sódio (Merck) na forma de lentilhas até que o valor do $\mathrm{pH}$ estivesse no intervalo entre 10 e 11 . O precipitado formado foi, então, separado por filtração a pressão reduzida (usando-se membranas de celulose de $0,45 \mu \mathrm{m}$ como material filtrante), seco, armazenado em recipiente de polietilieno hermeticamente fechado e mantido em local seco, bem ventilado e à temperatura ambiente.

\section{Determinação da concentração total de cromo nas soluções tratadas}

Após precipitação dos íons $\mathrm{Cr}(\mathrm{III})$ e $\mathrm{Fe}(\mathrm{III})$, a concentração de cromo total das soluções tratadas foi determinada por espectrometria de absorção atômica com chama (FAAS), usando um equipamento Varian (modelo AA240FS) equipado com lâmpada de deutério para correção da radiação de fundo e chama de ar-acetileno nas vazões de 13,5 $\mathrm{L} \mathrm{min}^{-1}$ e 3,40 L min ${ }^{-1}$, respectivamente. A fim de minimizar a interferência da matriz da amostra sobre o sinal analítico, foi empregado o método da adição de padrão. Na Tabela 1 são apresentados os valores de concentração final de $\mathrm{Cr}$ padrão adicionados em alíquotas das soluções tratadas com as diferentes porcentagens de palha de aço, para a obtenção dos pontos das curvas analíticas. As condições instrumentais foram otimizadas visando obter maior sensibilidade nos comprimentos de ondas avaliados. As soluções preparadas a partir das alíquotas das soluções tratadas foram analisadas nos comprimentos de onda de 357,9 e 520,5 nm (com resolução de 0,2 nm). A escolha de diferentes comprimentos de onda está relacionada às diferenças de concentração entre as soluções obtidas com os tratamentos. O comprimento de onda que oferece a maior sensibilidade, $357,9 \mathrm{~nm}$ ( $A=0,20$, para $2,5 \mathrm{mg} \mathrm{L}^{-1} \mathrm{de} \mathrm{Cr}$ ), foi utilizado para a quantificação 
do elemento nas soluções resultantes do tratamento com quantidade de palha de aço correspondente a $120 \%$ da estequiométrica. Em contrapartida, o comprimento de onda menos sensível, 520,5 nm ( $A=$ 0,20, para $1500 \mathrm{mg} \mathrm{L}^{-1} \mathrm{de} \mathrm{Cr}$ ), foi utilizado para quantificação nas amostras tratadas com quantidades de palha de aço correspondentes a $105 \%, 110 \%$ e $115 \%$ da estequiométrica.

Tabela 1. Valores da concentração final de cromo padrão $\left([\mathrm{Cr}]_{\mathrm{f}}\right)$ adicionada a alíquotas das soluções tratadas com diferentes quantidades de palha de aço (ferro) para a construção das curvas analíticas e consequente determinação da concentração de cromo total por FAAS

\begin{tabular}{cccccc}
\hline $\begin{array}{c}\text { Porcentagem de palha de } \\
\text { aço adicionada } \\
\left(m_{\mathrm{Fe}, \text { pratica }} / m_{\mathrm{Fe}, \text { estequiomérica }}\right) \times 100 \%\end{array}$ & \multicolumn{3}{c}{$[\mathrm{Cr}]_{\mathrm{f}} /\left(\mathrm{mg} \mathrm{L}^{-1}\right)$} & \\
\hline 105 & 0 & 250 & 500 & 1000 & --- \\
110 & 0 & 250 & 500 & 750 & --- \\
115 & 0 & 100 & 200 & 300 & --- \\
120 & 0 & 0,25 & 0,5 & 1,0 & 1,5 \\
\hline
\end{tabular}

\section{Determinação da concentração de cromo(VI) da solução tratada com $120 \%$ de palha de aço}

A concentração de íons Cr(VI) na solução tratada com 120\% de palha de aço foi determinada por espectrofotometria de absorção molecular no UV-Vis. Para tal, primeiramente foi preparada uma solução contendo $0,2 \mathrm{~g}$ do reagente 1,5-difenilcarbazida dissolvido em $100 \mathrm{~mL}$ de acetona contendo $1 \mathrm{~mL}$ de $\mathrm{H}_{2} \mathrm{SO}_{4} 10 \% \mathrm{~V} / \mathrm{V} .{ }^{1}$ Esta solução foi sempre preparada e utilizada no mesmo dia da leitura das amostras. As soluções para quantificação dos íons $\mathrm{Cr}$ (VI) foram preparadas adicionando-se 1,0 mL da solução de 1,5-difenilcarbazida em $\mathrm{H}_{2} \mathrm{SO}_{4}$ a $1,0 \mathrm{~mL}$ da amostra da solução tratada; os valores do $\mathrm{pH}$ e do volume final da solução resultante foram ajustados para 1 e $10 \mathrm{~mL}$, respectivamente. Para leitura em branco, $1 \mathrm{~mL}$ da solução de 1,5-difenilcarbazida em $\mathrm{H}_{2} \mathrm{SO}_{4}$ foi diluído para um volume final de $10 \mathrm{~mL}$ com ajuste do $\mathrm{pH}$ para 1 utilizando-se $\mathrm{H}_{2} \mathrm{SO}_{4}$ diluído. A concentração dos íons Cr(VI) foi, então, determinada com auxílio de um espectrofotômetro UV-Vis Femton (modelo 482) no comprimento de onda de $545 \mathrm{~nm}$, utilizando-se cubetas de quartzo com $1 \mathrm{~cm}$ de caminho óptico.

\section{RESULTADOS E DISCUSSÃO}

A Figura 1 ilustra uma curva típica de potencial em função do volume gasto de solução de sulfato ferroso amoniacal obtida durante a titulação potenciométrica de parte da solução residual diluída. A diminuição do valor de potencial decorre da variação dos valores de concentração das espécies químicas em solução, devido à reação química representada pela equação $2: 40$

$\mathrm{Cr}_{2} \mathrm{O}_{7}^{2-}(\mathrm{aq})+6 \mathrm{Fe}^{2+}(\mathrm{aq})+14 \mathrm{H}^{+}(\mathrm{aq}) \rightarrow 2 \mathrm{Cr}^{3+}(\mathrm{aq})+6 \mathrm{Fe}^{3+}(\mathrm{aq})+7 \mathrm{H}_{2} \mathrm{O}(\mathrm{l})$

Como descrito na equação (2) e também na equação (1), as reações entre os íons dicromato e ferroso e íons dicromato e ferro metálico envolvem quantidades apreciáveis de íons hidrogênio; daí a necessidade de se adicionar, na alíquota de solução residual a ser titulada, soluções concentradas de ácidos sulfúrico e fosfórico. A presença do ácido fosfórico também é importante para diminuir a concentração de íons $\mathrm{Fe}^{3+}$ em solução por meio da formação do complexo $\mathrm{FeHPO}_{4}{ }^{+}$, favorecendo as reações representadas pelas equações (1) e (2) $\cdot^{40}$ No caso da titulação potenciométrica ilustrada na Figura 1, o volume de solução de sulfato ferroso amoniacal correspondente

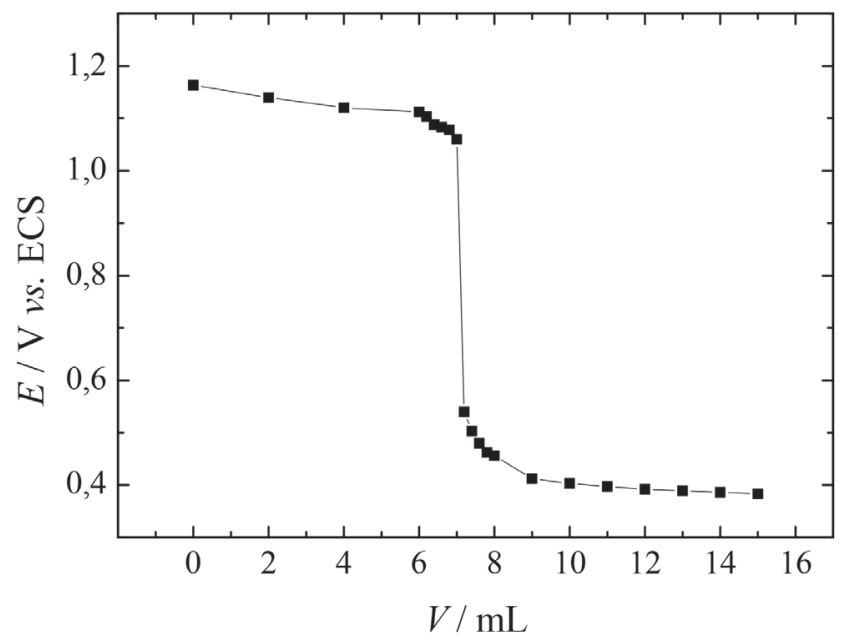

Figura 1. Curva típica de potencial em função do volume de solução de sulfato ferroso amoniacal 0,103 mol $\mathrm{L}^{-1}$ obtida para a titulação de uma alíquota de $10 \mathrm{~mL}$ de solução residual diluída por um fator de 100, utilizando Pt como eletrodo indicador

ao ponto final da titulação (próximo ao ponto de equivalência) foi obtido pelo método da segunda derivada $\left(\mathrm{d}^{2} E / \mathrm{d} V^{2}\right)$, resultando em 7,1 $\pm 0,1 \mathrm{~mL}$, para três curvas de titulação. Consequentemente, a concentração de íons $\mathrm{Cr}(\mathrm{VI})$ presentes na solução residual resultou em $2,4 \mathrm{~mol} \mathrm{~L}^{-1}$, um valor um pouco inferior àquele das soluções empregadas nos processos de coloração de aços inoxidáveis $\left(2,5 \mathrm{~mol} \mathrm{~L}^{-1}\right)$. Este resultado era esperado, pois uma parte dos íons dicromato da solução é consumida na eletrocoloração dos aços.

Como já mencionado anteriormente, uma parte da solução residual diluída também foi submetida a uma titulação potenciométrica de forma idêntica àquela ilustrada na Figura 1; a única diferença foi o uso da palha de aço (ferro) como titulante no lugar da solução de sulfato ferroso amoniacal. Para isto, pequenas quantidades de palha de aço previamente pesadas foram adicionadas à solução residual diluída, monitorando-se o potencial do eletrodo indicador de platina. A Figura 2 ilustra uma curva típica de potencial em função da razão mássica de palha de aço efetivamente adicionada em relação à massa de ferro necessária para reagir completamente com os íons dicromato,

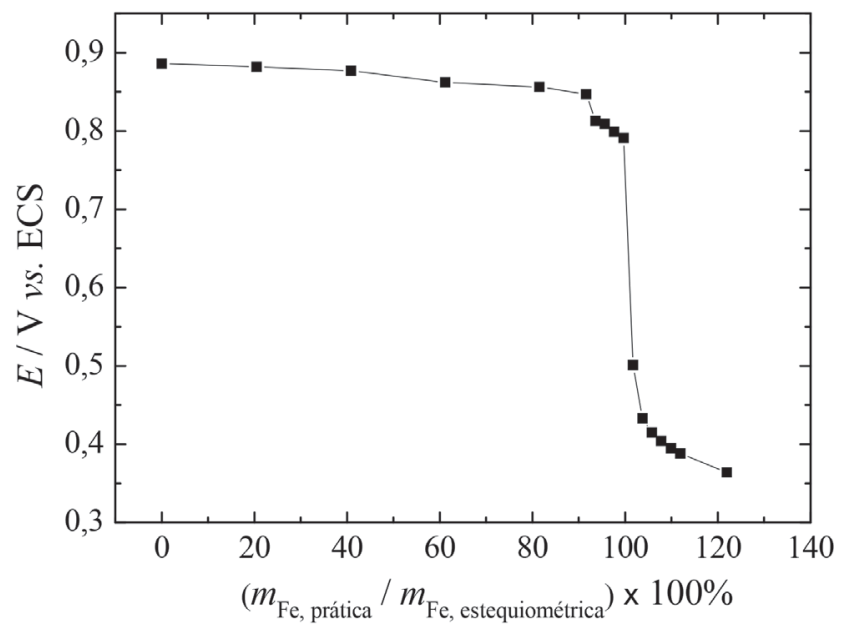

Figura 2. Curva típica de potencial em função da fração mássica de palha de aço (ferro) efetivamente adicionada a uma alíquota de 1 L de solução residual (diluída por um fator de 100), utilizando Pt como eletrodo indicador. A fração mássica de palha de aço (ferro) foi calculada em relação à massa de ferro necessária para reagir completamente com os íons dicromato, de acordo com a equação (1) - vide texto 
de acordo com a equação (1) (quantidade estequiométrica), isto é, $m_{\mathrm{Fe} \text {, prática }} / m_{\mathrm{Fe} \text {, estequiométrica }} \times 100 \%$. Nesta figura, os valores iniciais de potencial são menores do que aqueles na Figura 1 porque a concentração de íons hidrogênio na solução titulada é menor do que aquela na solução titulada com o sulfato ferroso amoniacal, conforme está descrito na parte experimental.

De acordo com Özer et al., ${ }^{3}$ a reação entre os íons dicromato e ferro metálico em meio ácido (equação (1)) ocorre em duas etapas, sendo a primeira representada pela equação:

$2 \mathrm{Cr}_{2} \mathrm{O}_{7}^{2-}(\mathrm{aq})+6 \mathrm{Fe}(\mathrm{s})+28 \mathrm{H}^{+}(\mathrm{aq}) \rightarrow 4 \mathrm{Cr}^{3+}(\mathrm{aq})+6 \mathrm{Fe}^{2+}(\mathrm{aq})+14 \mathrm{H}_{2} \mathrm{O}(\mathrm{l})$

e a segunda representada pela equação (2). Quando estas duas equações são somadas e divididas por três, obtém-se a equação (1), que representa, portanto, a reação global do processo. Özer et al. ${ }^{3}$ investigaram detalhadamente o processo de redução de íons dicromato em meio ácido, utilizando palha de aço como agente redutor. Neste estudo, a solução contendo íons dicromato foi forçada a passar, a uma dada vazão, por um reator contendo uma quantidade conhecida de palha de aço (ferro) suportada por placas porosas de vidro. Dos resultados obtidos, concluíram que a extensão do processo de redução dos íons $\mathrm{Cr}(\mathrm{VI})$ aumenta com a concentração inicial de ácido; assim, um excesso de $50 \%$ de ácido foi adotado pelos autores. Os demais parâmetros estudados (concentração inicial de íons $\mathrm{Cr}(\mathrm{VI})$, vazão de eletrólito e temperatura) não apresentaram efeitos significativos no processo. Tendo em conta esses resultados, o tratamento da solução residual usando palha de aço no presente trabalho também foi realizado com um excesso de ácido de cerca de 50\%. É importante ressaltar que a obtenção da curva de titulação ilustrada na Figura 2 é bastante demorada, dada a lenta estabilização do valor de potencial do eletrodo indicador, principalmente na região próxima ao ponto de equivalência ( 6 a 8 h). Isto decorre da cinética bastante lenta da reação global do processo (equação (1)).

A partir da curva de titulação ilustrada na Figura 2, observa-se a necessidade de uma quantidade de palha de aço (ferro) maior do que a quantidade estequiométrica para tratar completamente os íons dicromato contidos na solução residual. Isto ocorre devido à presença de impurezas na palha de aço comercial e a uma possível reação entre os íons ferroso produzidos na primeira etapa do processo (equação 3 ) e o oxigênio dissolvido na solução. ${ }^{41}$ Tendo em conta esse resultado, a eficiência do processo de tratamento da solução residual foi avaliada para quantidades de palha de aço correspondentes a 105\%, 110\%, $115 \%$ e $120 \%$ da estequiométrica. Nestes tratamentos, pequenas quantidades de palha de aço foram adicionadas à solução residual até que a massa total requerida fosse atingida, mantendo-se sempre a mistura sob agitação magnética e em banho de água à temperatura ambiente. Antes de cada nova adição, sempre se esperava o consumo completo da palha de aço previamente adicionada. Os íons $\mathrm{Cr}(\mathrm{III}) \mathrm{e}$ $\mathrm{Fe}(\mathrm{III})$ produzidos no processo (equação (1)) foram, então, completamente precipitados pela adição de hidróxido de sódio, conforme descrito na seção experimental. Giovannini et al. ${ }^{21}$ avaliaram técnicas de precipitação química de resíduos líquidos contendo cromo (solução muito semelhante à do presente trabalho). $\mathrm{O}$ tratamento utilizado consistiu na redução de íons $\mathrm{Cr}$ (VI) a $\mathrm{Cr}$ (III) em meio ácido, adicionando solução de tiossulfato de sódio com posterior precipitação daqueles íons a $\mathrm{Cr}(\mathrm{OH})_{3}$. Dada a presença de outros íons na solução residual (mesma situação da solução tratada no presente trabalho), os autores verificaram que o melhor intervalo de $\mathrm{pH}$ para a remoção de cromo por precipitação química se situa entre 10 e 11; neste intervalo de $\mathrm{pH}$, a eficiência de remoção de cromo avaliada por espectrometria de emissão óptica com plasma acoplado indutivamente foi praticamente $100 \%$. Daí o fato da precipitação dos íons $\mathrm{Cr}(\mathrm{III})$ a $\mathrm{Cr}(\mathrm{OH})_{3}$ no presente trabalho ter sido realizada no intervalo de $\mathrm{pH}$ entre 10 e 11.
Os valores obtidos de concentração total de cromo determinada por FAAS para as soluções residuais tratadas com quantidades de palha de aço correspondentes a 105\%, 110\%, 115\% e $120 \%$ em relação à quantidade estequiométrica foram os seguintes: $5410 \pm 9$, $2056 \pm 3,772 \pm 3$ e $0,29 \pm 0,02 \mathrm{mg} \mathrm{L}^{-1}(\mathrm{n}=3)$, respectivamente. Desta forma, observa-se que a solução tratada com excesso de palha de aço de $20 \%$ em relação ao valor estequiométrico teórico apresenta um valor de concentração de cromo total menor que o limite máximo estabelecido pelo CONAMA para efluentes industriais $\left(1,1 \mathrm{mg} \mathrm{L}^{-1} \mathrm{Cr}\right)$. Como mencionado na seção experimental, a concentração de $\mathrm{Cr}(\mathrm{VI})$ das soluções residuais tratadas também foi determinada por espectrofotometria no UV-Vis utilizando-se o reagente 1,5-difenilcarbazida. Consequentemente, a concentração residual de íons $\mathrm{Cr}$ (III) foi calculada pela diferença entre as concentrações de cromo total e de íons Cr(VI). Para a solução residual que foi tratada com quantidade de palha de aço correspondente a $120 \%$ da estequiométrica, a concentração de íons $\mathrm{Cr}(\mathrm{VI})$ encontrada foi menor que $0,01 \mathrm{mg} \mathrm{L}^{-1}$, um valor bem inferior ao limite máximo estabelecido pelo CONAMA para efluentes industriais $\left(0,1 \mathrm{mg} \mathrm{L}^{-1}\right)$. Isto permite inferir que a concentração de íons $\mathrm{Cr}$ (III) na solução tratada é estatisticamente igual àquela de cromo total $\left(0,29 \pm 0,02 \mathrm{mg} \mathrm{L}^{-1}\right) \mathrm{e}$, portanto, bem abaixo do limite máximo estabelecido pelo CONAMA $\left(1,0 \mathrm{mg} \mathrm{L}^{-1}\right)$. Estes resultados comprovam a eficiência da metodologia proposta no presente trabalho para o tratamento de soluções residuais que contêm altas concentrações de ácido e de íons $\mathrm{Cr}(\mathrm{VI})$ na forma de íons dicromato, $\mathrm{Cr}_{2} \mathrm{O}_{7}{ }^{2-}$. Além disso, o emprego de palha de aço comercial como agente redutor nesta metodologia apresenta, ainda, as seguintes vantagens: i) tratamento mais rápido da solução residual tendo em conta a grande área superficial dos fios que compõem a palha de aço comercial $\left(n^{\circ} 0\right)$ quando comparado àquele que utiliza limalhas de ferro metálico (testadas e abandonadas no presente trabalho por apresentarem baixa velocidade de reação) e; (ii) praticidade na execução do tratamento em função das facilidades de aquisição e manuseio de palhas de aço comerciais. Cabe destacar que a solução tratada (uma solução concentrada de sulfato de sódio contendo baixas concentrações de impurezas metálicas) pode ser utilizada para diferentes fins, ajustando seu pH e/ou concentração. Exemplos de possíveis aplicações para a solução tratada incluem: ${ }^{42}$ i) formulação de soluções eletrolíticas empregadas em eletrólises, pois aumenta a condutividade destas soluções e diminui, consequentemente, o potencial de célula, tais como nos processos de eletroxidação de compostos orgânicos, eletrodeposição de metais sobre substratos diversos e geração dos gases hidrogênio e oxigênio; ii) obtenção de outros produtos químicos, tais como carbonato ou monohidrogenocarbonato de sódio e sulfato de potássio e; iii) formulação de detergentes empregados na limpeza de carpetes e tapetes.

Como mencionado na parte experimental, a solução residual que foi tratada continha predominantemente íons dicromato, $\mathrm{Cr}_{2} \mathrm{O}_{7}{ }^{2-}$, e os íons dos elementos de liga que compõem o aço inoxidável austenítico, tais como ferro, níquel, cromo, manganês etc. Portanto, após a etapa de precipitação com hidróxido de sódio, é de se esperar que, além de $\mathrm{Fe}(\mathrm{OH})_{3}$ e $\mathrm{Cr}(\mathrm{OH})_{3}$, o resíduo sólido formado também contenha $\mathrm{Ni}(\mathrm{OH})_{2}, \mathrm{Mn}(\mathrm{OH})_{2}$ etc., porém em menor quantidade. De acordo com Belebchouche et al.,${ }^{43}$ uma das técnicas amplamente empregadas para a disposição final de resíduos perigosos contendo metais tóxicos é a de encapsulamento por meio de aglutinantes hidráulicos. Este processo consiste em reduzir a toxicidade de um resíduo sólido, convertendo-o em um material de menor solubilidade, tornando-o menos móvel e, consequentemente, menos tóxico. Estes autores relataram a utilização desta técnica no encapsulamento de um resíduo contendo níquel, cromo e chumbo por meio de um aglutinante hidráulico em duas diferentes formulações: argamassas e pastas de cimento. Em testes de lixiviação, 
as argamassas apresentaram melhor eficiência no encapsulamento do resíduo tóxico do que as pastas de cimento.

\section{CONCLUSÕES}

A metodologia usada no presente trabalho empregando palha (lã) de aço comercial apresentou resultados eficientes para uma redução significativa da toxicidade de soluções residuais contendo altas concentrações de ácido e de íons $\mathrm{Cr}(\mathrm{VI})$ na forma de íons dicromato, $\mathrm{Cr}_{2} \mathrm{O}_{7}{ }^{2-}$. O tratamento de uma solução residual empregada em processos de eletrocoloração de aços inoxidáveis (mistura do ácido sulfúrico $5,0 \mathrm{~mol} \mathrm{~L}^{-1}$ e anidrido crômico/trióxido de cromo 2,5 $\mathrm{mol} \mathrm{L}^{-1}$ ), utilizando-se um excesso de palha de aço de $20 \%$ em relação à quantidade estequiométrica como agente redutor e hidróxido de sódio como precipitante (até pH 10-11), produziu uma solução tratada na qual os valores de concentração de cromo trivalente e hexavalente foram $0,29 \pm 0,02 \mathrm{mg} \mathrm{L}^{-1} \mathrm{e}<0,01 \mathrm{mg} \mathrm{L}^{-1}$, respectivamente, os quais são bem inferiores aos limites máximos estabelecidos pelo CONAMA para efluentes industriais. Portanto, tal metodologia pode ser utilizada de forma prática e eficiente para o tratamento de soluções residuais ácidas contendo cromo hexavalente geradas em laboratórios de Química, seja no contexto geral de tratamento de resíduos ou de um experimento didático para estudantes.

\section{AGRADECIMENTOS}

À FAPESP pelo auxílio financeiro (proc. 99/12576-5) e à CAPES e ao $\mathrm{CNPq}$ pelas bolsas concedidas. Os autores também agradecem aos professores Dr. Edenir R. Pereira Filho e Dr. Joaquim A. Nóbrega por concederem que parte deste trabalho fosse realizado no laboratório do Grupo de Análise Instrumental Aplicada do Departamento de Química da UFSCar.

\section{REFERÊNCIAS}

1. Matos, W. O.; Nóbrega, J. A.; Souza, G. B.; Nogueira, A. R. A.; Quim. Nova 2008, 31, 1450.

2. Rajeshwar, K; Ibanez, J. G.; Environmental Electrochemistry. Fundamentals and Applications in Pollution Abatement, Academic Press: San Diego, 1996.

3. Özer, A.; Altundoğan, H. S.; Erdem, M.; Tümen, F.; Environ. Pollut. 1997, 97, 107.

4. Devilliers, D.; Dinh Thi, M. T.; Mahé, E.; Le Xuan, Q.; Electrochim. Acta 2003, 48, 4301.

5. Andrade, L. S.; Xavier, S. C.; Rocha-Filho, R. C.; Bocchi, N.; Biaggio, S. R.; Electrochim. Acta 2005, 50, 2623.

6. Conrrado, R.; Bocchi, N.; Rocha-Filho, R. C.; Biaggio, S. R.; Electrochim. Acta 2003, 48, 2417.

7. Kikuti, E.; Conrrado, R.; Bocchi, N.; Biaggio, S. R.; Rocha-Filho, R. C.; J. Braz. Chem. Soc. 2004, 15, 472.

8. Kikuti, E.; Bocchi, N.; Ferreira, M. G. S.; Belo, M. C.; Carmezim, M. J.; Cienc. Tecnol. Mater. 2005, 17, 23.

9. Taveira, L. V.; Kikuti, E.; Bocchi, N.; Dick, L. F. P.; J. Electrochem. Soc. 2006, 153, B411.

10. Kikuti, E.; Bocchi, N.; Pastol, J. L.; Ferreira, M. G.; Montemor, M. F.; Belo, M. C.; Simões, A. M.; Corros. Sci. 2007, 49, 2303.

11. Vasconcelos, K. O.; Bocchi, N.; Simões, A. M.; J. Braz. Chem. Soc. 2010, 21, 469.
12. Corredor, J.; Bergmann, C. P.; Pereira, M.; Dick, L. F. P.; Surf. Coat. Technol. 2014, 245, 125.

13. Jin, W.; Du, H.; Zheng, S.; Zhang, Y.; Electrochim. Acta 2016, 191, 1044.

14. Xie, B.; Shan, C.; Xu, Z.; Li, X.; Zhang, X.; Chen, J.; Pan, B.; Chem. Eng. J. 2017, 308, 791.

15. Ferreira, A. D. Q.; Quim. Nova 2002, 25, 572.

16. http://www.mma.gov.br/port/conama/res/res 11/propresol_ lanceflue_30e31mar11.pdf, acessado em outubro de 2017.

17. Pettine, M.; Campanella, L.; Millero, F. J.; Environ. Sci. Technol. 2002, 36, 901.

18. Chang, L. Y.; Environ. Prog. 2003, 22, 174.

19. Su, C.; Ludwig, R. D.; Environ. Sci. Technol. 2005, 39, 6208.

20. Goshu, I. V.; Tsarev, Y. V.; Kostrov, V. V.; Russ. J. Appl. Chem. 2007, 80, 2024.

21. Giovannini, J. G.; Tavares, G. A.; Bendassolli, J. A.; Quim. Nova 2008 , $31,676$.

22. Gromboni, C. F.; Donati, G. L.; Matos, W. O.; Neves, E. F. A.; Nogueira, A. R. A.; Nóbrega, J. A.; Environ. Chem. Lett. 2010, 8, 73.

23. Paula, L. N.; Giusto, L. A. R.; Rodrigues-Filho, R. C.; Castilho, L. R.; Magalhães, F.; Quim. Nova 2013, 36, 1332.

24. Mitra, P.; Banerjee, P.; Sarkar, D.; Chakrabarti, S.; Int. J. Environ. Sci. Technol. 2014, 11, 449.

25. Yu, R.-F.; Chi, F.-H.; Cheng, W.-P.; Chang, J. C.; Chem. Eng. J. 2014, $255,568$.

26. Villacís-García, M.; Villalobos, M.; Gutiérrez-Ruiz, M.; J. Hazard. Mater. 2015, 281, 77 .

27. Lin, W. Y.; Wei, C.; Rajeshwar, K.; J. Electrochem. Soc. 1993, 140, 2477.

28. Wang, L.; Wang, N.; Zhu, L.; Yu, H.; Tang, H.; J. Hazard. Mater. 2008, $152,93$.

29. Machado, T. C.; Lansarin, M. A.; Matte, N.; Water Sci. Technol. 2014, 70,55 .

30. Ruotolo, L. A. M.; Santos-Júnior, D. S.; Gubulin, J. C.; Water Res. 2006, 40, 1555

31. Tian, Y.; Yang, F.; J. Cleaner Production 2007, 15, 1415.

32. Roberts, E. P. L.; Yu, H.; J. Appl. Electrochem. 2002, 32, 1091.

33. Frenzel, I.; Holdik, H.; Barmashenko, V.; Stamatialis, D. F.; Wessling, M.; J. Appl. Electrochem. 2006, 36, 323.

34. Rodriguez-Valadez, F.; Ortiz-Éxiga, C.; Ibánez, J. G.; Alatorre-Ordaz, A.; Gutierrez-Granados, S.; Environ. Sci. Technol. 2005, 39, 1875.

35. Welch, C. M.; Nekrassova, O.; Compton, R. G.; Talanta 2005, 65, 74.

36. Wang, H.; Ren, Z. J.; Water Res. 2014, 66, 219.

37. Vendruscolo, F.; Ferreira, G. L. R.; Antoniosi-Filho, N. R.; Int. Biodeterior. Biodegrad. 2017, 119, 87.

38. Bertagnolli, C.; Silva, M. G. C.; Guibal, E.; Chem. Eng. J. 2014, 237 , 362.

39. Sen, M.; Dastidar, M. G.; Iran. J. Environ. Health. Sci. Eng. 2010, 7, 182.

40. Baccan, N.; Andrade, J. C.; Química Analítica Quantitativa Elementar, $3^{\text {a }}$ ed., Edgard Blucher: São Paulo, 2004. pp. 238-240.

41. Eary, L. E.; Rai, D.; Environ. Sci.Technol. 1988, 22, 972.

42. Garret, D. E.; Sodium Sulfate Handbook of Deposits, Processing, Properties, and Uses, Academic Press: Cambridge, 2001. pp. 289-302.

43. Belebchouche, C.; Moussaceb, K.; Aït-Mokhtar, A.; European Journal of Environmental and Civil Engineering 2016, 20, 711. 